\title{
Estratégias de internacionalização - Estudo de caso para empresas portuguesas
}

\author{
Internationalization strategies - A study case for Portuguese firms
}

Raquel Pereira ${ }^{1}$; Marlene Pinto².

\author{
${ }^{1}$ E-mail: rpereira@ iscap.ipp.pt \\ Instituto Politécnico do Porto, CEOS.PP; \\ Instituto Superior de Contabilidade e \\ Administração do Porto.
}

${ }^{2}$ E-mail: marlenearpinto@ hotmail.com Instituto Superior de Contabilidade e Administração do Porto.
Resumo: A temática da internacionalização mantém-se amplamente debatida sendo considerada uma estratégia chave para a competitividade das empresas e das economias. No contexto português, em que se verifica uma evolução favorável e sustentada das exportações, há vários anos, a internacionalização e diversificação de mercados assume um papel fundamental para a sustentabilidade das empresas. Usando a metodologia qualitativa, pretendemos analisar o processo de internacionalização de três PME portuguesas no sentido de perceber a sua abordagem aos mercados internacionais. Os resultados apontam algumas evidências sobre a utilidade da literatura revista. O modelo Uppsala parece ser útil para compreender parte do Processo de Internacionalização (PI) das PME. Não obstante, há empresas que iniciam a expansão internacional muito rapidamente, para mercados muito dispersos, divergindo com alguns princípios do modelo Uppsala. Para as empresas em análise, a exportação constitui o principal modo de entrada e as razões que determinam o PI estão associadas ao perfil do gerente, ao modelo de negócios e às networks de que a empresa poderá fazer parte.

Palavras-chave: Estratégias; Internacionalização; PME; Teorias de Internacionalização.

Abstract: Internationalization remains widely debated as it is seen as a key strategy for the competitiveness of companies and economies. In the Portuguese context, where there has been a favorable and sustained evolution of exports for several years, the internationalization and diversification of markets seems to play a fundamental role for the sustainability of companies. Following a qualitative methodology, our goal is to analyze the internationalization process of three SMEs to find out how they approach the international markets. The results suggest some evidence concerning the usefulness of the reviewed literature. They indicate that Uppsala model is useful to understand part of the SMEs IP. However, they also indicate that some firms begin their IP very quickly to dispersed markets, diverging from some of the principles of the Uppsala model. For the firms under study, exporting is the main strategy or entry mode in the external markets and the reasons to begin the IP are related to factors such as the manager's profile, the business model and the networks which the company may be a part of.

Keywords: $\quad$ Strategies; $\quad$ Internationalization; $\quad S M E$; Internationalization Theories. 


\section{pontěditora}

\section{a) Introdução e objetivos}

Num quadro de globalização, em que a concorrência advém tanto de mercados e economias desenvolvidas como emergentes, a internacionalização assume uma primordial importância para a competitividade das mesmas.

De facto, a rápida e constante evolução do contexto mundial em que as empresas competem tem sido determinante para justificar a relevância que a internacionalização assume no quadro das estratégias empresariais atuais. No caso português, esta afirmação assume particular pertinência. $\mathrm{O}$ tecido empresarial em Portugal é fortemente caracterizado por Pequenas e Médias Empresa (PME) ${ }^{1}$ sendo a sua internacionalização determinante para o desempenho ao nível do comércio internacional mas também da nossa Economia, dada a importância que estas assumem ao nível do emprego e do Valor Acrescentado Bruto. Também o relatório final da Comissão Europeia (2010) indica que a internacionalização traz muitos benefícios, não apenas às empresas mas também às economias envolvidas.

Estes factos justificam o interesse e a pertinência em estudar e analisar o processo de internacionalização adotado pelas PME portuguesas. Em concreto, neste trabalho analisamos o caso de três PME que operam em áreas de negócio completamente distintas: o caso da empresa Arcaboa - Indústria de frio, SA, que se dedica ao fabrico de equipamentos não domésticos de refrigeração; o caso Paulo Antunes - Unipessoal, Lda., que atua no setor do mobiliário e decoração; e o caso VentureOak, do ramo da programação informática. A opção de escolher PME justifica-se pela relevância que estas empresas assumem na Economia do nosso país. Adicionalmente, não podemos esquecer que para a grande parte das PME, a falta de recursos humanos e financeiros, de experiência e conhecimento limita o processo de internacionalização (PI), além de que estão mais expostas a choques internos e externos (Amal, M; Filho, A. \& Miranda, C., 2008; Jarillo, 1989; Knight, 2000). Por outro lado, a escolha de casos de ramos de atividade muito distintos poderia, à partida, evidenciar diferenças na forma como abordam os mercados internacionais.

\footnotetext{
${ }^{1}$ Os critérios que definem uma PME estão apresentados na recomendação da Comissão Europeia: EU recommendation 2003/361.
} 


\section{pontěditora}

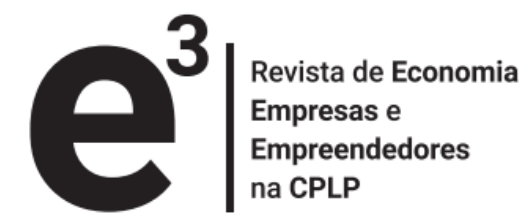

Este trabalho começa por fazer, na primeira secção, um enquadramento teórico que tem por base a revisão da literatura existente sobre a temática. Fundamentalmente, procuramos explanar e compreender as teorias, motivos e fases do PI. Na segunda secção é explicada a metodologia utilizada e a terceira secção apresenta e analisa os três casos de internacionalização referidos. Utilizando a metodologia qualitativa, através do estudo de caso, os objetivos fundamentais são analisar e perceber, fazendo o enquadramento com a teoria e a literatura revista, de que forma as PME abordam os mercados internacionais procurando, dessa forma, dar resposta às questões de investigação propostas: Que factores motivam e influenciam o PI? Que estratégias e modalidades escolhem? Que factores de diferenciação possuem que lhes permitem competir nos mercados internacionais? Por último, são apresentadas as principais conclusões, bem como as limitações e sugestões para trabalhos futuros.

\section{b) Marco teórico de referência}

A crescente interdependência das Economias e o rápido processo de globalização forçaram as empresas a concorrerem num mercado global e em permanente mudança, determinando novos e constantes desafios nos negócios. De facto, os acontecimentos das últimas décadas determinaram um renovado e justificado interesse nas temáticas da globalização e internacionalização. Assim o afirmam Hagiu e Clipici (2009, p. 375), "As a result of growing globalization and competition the issue of internationalization is becoming more and more important and relevant for companies all over the world". Também Conconi, Spair and Zanardi (2015, p. 16), “in recent decades, more and more companies have started to operate outside their domestic markets, exporting their goods to foreign customers and engaging in foreign direct investment (FDI)".

Portanto, o mercado é global e a concorrência advém tanto de mercados e economias desenvolvidas como emergentes. A internacionalização assume, por isso, primordial importância para a competitividade das mesmas. Mas porque é que as que as empresas se internacionalizam? Que motivos determinam esse processo? De que forma as empresas o fazem? 


\section{pontěditora}

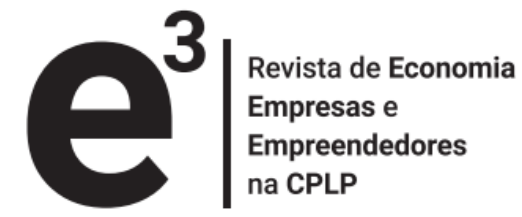

\section{b1) Teorias e modelos de internacionalização}

Ao analisar o PI de uma empresa, é importante confrontar modelos teóricos com a prática empresarial. Isto é, para que haja um conhecimento mais profundo dos motivos que levam as empresas a internacionalizar-se, assim como as estratégias e modalidades utilizadas, é necessário analisar algumas das principais teorias explicativas, desta temática, que continuam a ser a base de vários trabalhos empíricos e académicos. Ao fazê-lo, procuraremos confrontar e verificar a validade das teorias e literatura relevantes com os casos em análise.

A revisão da literatura das teorias de internacionalização permite agrupar essas teorias/modelos em três categorias principais:

a) As que assentam numa abordagem económica, na medida em que são modelos mais orientados para a otimização dos recursos e dos retornos financeiros (Anderson e Buvik, 2002). A Teoria da Internalização (Buckley \& Casson, 1998) e o Paradigma Eclético de Dunning (1988), enquadram-se nesta abordagem;

b) As que defendem que os processos de internacionalização se realizam por etapas e de forma gradual, como o modelo de Uppsala (Johanson \& Wiedersheim-Paul, 1975); Johanson e Vahlne (1977) e o modelo Uppsala na perspetiva das Networks (Johanson \& Vahlne, 2009). Estes modelos seguem uma abordagem comportamentalista, onde o processo de internacionalização está mais relacionado com as atitudes, perceções e comportamentos da empresa (Anderson e Buvik, 2002).

c) As que procuram analisar e explicar "como" e o "porquê" de algumas empresas abordarem o mercado externo desde muito cedo. São as designadas Born Globals ou International New Ventures (INV) (Welch \& Loustarinen, 1988; Rennie, 1993; Oviatt \& McDougall, 1994)

As teorias que se baseiam numa abordagem económica procuram, fundamentalmente, analisar as determinantes e estratégias de Investimento Direto Estrangeiro (IDE). Desenvolvida por Buckley e Casson (1976), a Teoria da Internalização recorre ao conceito de "imperfeições de mercado" contribuindo para a compreensão das atividades 


\section{pontěditora}

de IDE das empresas e para fomentar a ideia que as multinacionais demonstram maior eficiência que o mercado na organização de atividades económicas. Similarmente, o Paradigma Eclético de Dunning ou Paradigma OLI (Onwership-LocalizationInternalization) procurava ainda identificar de que forma as operações das empresas multinacionais se desenvolviam no país recetor ("Como"?), no sentido de perceber o seu maior sucesso comparativamente às empresas locais. Sendo um dos modelos teóricos mais reconhecidos em negócios internacionais (Stoian \& Filippaios, 2008), o paradigma de Dunning $(1973,2000)$, procura explicar a forma, extensão e padrão do processo de internacionalização através do IDE. Na génese da existência e sucesso de uma empresa multinacional, está o facto da sua vantagem competitiva ser suficiente para ultrapassar os custos e desvantagens de ser estrangeira. Essa empresa precisa criar mais valor acrescentado que as empresas domésticas, até porque tem que ter em conta os custos de se instalar e operar no estrangeiro.

A abordagem económica destas teorias, ao focalizar-se nas empresas multinacionais e nas determinantes e estratégias do IDE, ficam sujeitas a críticas. Além de avaliar a internacionalização de forma estática não relevando, por exemplo, outras formas de colaboração interempresariais, centram-se no IDE e nas empresas multinacionais, esquecendo-se das empresas de menor dimensão (Anderson 1997). Além disso, a existência de diversos critérios de decisão (risco, retorno, controlo e recursos) faz com que a decisão do modo de entrada acabe por ser complexo.

O modelo de Uppsala, desenvolvido por Johanson e Wiedersheim-Paul (1975) e posteriormente complementado por Johanson e Vahlne (1977), procura explicar e prever diferentes padrões de comportamento no processo de internacionalização. $O$ processo de internacionalização é considerado um processo pelo qual a empresa aumenta gradualmente o seu envolvimento internacional. Assim, segundo o modelo, existe uma interação entre o desenvolvimento do conhecimento adquirido sobre os mercados externos e o comprometimento da empresa com as suas decisões e operações comerciais. A introdução do conceito de conhecimento de mercado diz respeito ao resultado da experiência adquirida durante um processo de internacionalização e é de suma importância para futuras decisões na escolha de mercados-alvo, na medida em que o conhecimento de mercado ajuda a empresa a identificar os riscos e oportunidades 


\section{pontěditora}

provenientes de um mercado específico (Johanson \& Vahlne, 1977, p. 27). Segundo Benito e Gripsrud (1992), os autores introduziram ainda no modelo, o conceito de "distância psicológica" que engloba factores como: a linguagem, sistemas políticos, educação, desenvolvimento industrial; e as distâncias culturais com vista a analisar a distância entre o país de origem e o mercado-alvo, uma vez que estes factores podem dificultar ou facilitar os fluxos de informação entre a empresa e um mercado específico. A distância geográfica é vista também como uma ferramenta importante que, apesar de ser englobada no conceito de "distância psicológica" (Johanson \& Wiedersheim-Paul, 1975), parece ser independente, pois os países que se encontram próximos geograficamente podem revelar grandes distâncias psicológicas (como por exemplo, a distância política e cultural). Além disso, quanto maior for a diferença da "distância psicológica" entre o país de origem e o país estrangeiro, maior será a incerteza entre os dois países. Devido a estas incertezas e às imperfeições dos canais de informação, a expansão geográfica das empresas dá-se preferencialmente em mercados cujas similaridades com o mercado interno são mais evidentes (Johanson \& Vahlne, 1977).

Portanto, para os autores, o PI é um processo incremental, do qual a empresa beneficia de uma aprendizagem sucessiva, que pode ser levada a cabo por uma sequência de modos de entrada em novos mercados de forma gradual, e progressiva, começando na exportação esporádica e terminando com a criação de uma subsidiária no exterior. Em conclusão, segundo este modelo, o processo de internacionalização constitui um processo de aprendizagem experimental e de compromisso incremental o que significa que, à medida que o conhecimento dos mercados externos aumenta, também aumenta o grau de comprometimento da empresa nesses mercados, permitindo uma melhor e mais eficiente exploração das oportunidades que os mesmos oferecem.

A rápida evolução ocorrida no contexto dos negócios e estratégias empresariais, decorrente da globalização, permitiu constatar que nem todas as empresas se expandiam geograficamente de acordo com a lógica "step-by-step". Nesse sentido, Johanson e Vahlne (2009) procederam à revisão do modelo original de Uppsala. Da revisão surgiu o conceito de rede de negócios. "The main change in the model is the network concept and its role in the internationalization process" (Ducuing, \& Gallo, 2010, p.14). Surge, assim, a Teoria das Redes de Relacionamentos (networks). Isto significa que, a 


\section{pontěditora}

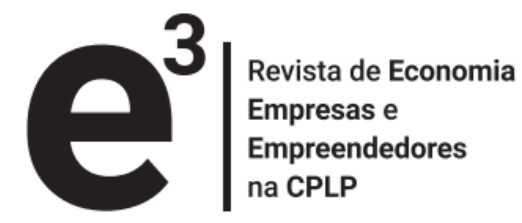

experiência adquirida e o comprometimento de mercado dependem agora do potencial dos parceiros e da sua rede de negócios. Nesta perspetiva, a questão das relações entre o comprometimento, o conhecimento, as redes de negócios e a forma como elas se interrelacionam para encontrar novas oportunidades são o cerne da nova concetualização dos autores (Johanson \& Vahlne, 2006, p.165).

Embora seja reconhecida a relevância desta teoria, no âmbito dos negócios internacionais, ela foi sujeita a críticas, sobretudo no que se refere à sua falta de capacidade para descrever e explicar alguns processos contemporâneos e rápidos de internacionalização, como por exemplo o caso das empresas de e-commerce ou Born Global.

Over the last two decades, the observation that an increasing number of firms aim for international markets right from their start has seriously challenged the stage model. (Cannone \& Ughetto, 2014, p. 272)

Considerando a literatura revista, relativa às designadas Born Globals, podemos dizer que estas se caraterizam por ser empresas jovens e de pequena e média dimensão, que surgem de um cenário competitivo, caraterizado por um mundo globalizado e dinâmico, e que possuem grande proporção de vendas oriundas de mercados externos, nos quais começam a atuar aquando da sua origem ou pouco tempo depois. Dessa forma, demonstram que a sua internacionalização é feita de um modo acelerado, não seguindo o padrão de "estágios" para a sua internacionalização. Segundo Hennart (2014), foram autores como Welch e Loustarinen (1988), Rennie (1993) e Oviatt e McDougall (1994) que, ao longo das últimas décadas, identificaram um número crescente de empresas, que não seguiam o padrão tradicional de um processo de internacionalização. Pelo contrário, as empresas começavam logo a promover atividades internacionais desde a sua génese ou pouco tempo depois.

Conhecidas por Born Globals (Rennie, 1993) ou por International New Ventures (INV) (McDougall \& Oviatt, 1994) estes casos divergem de uma das principais referências sobre a internacionalização - o modelo Uppsala. Neste modelo, a internacionalização é um processo lento e moroso, mas as INV internacionalizam-se rapidamente e tendem a assumir riscos elevados durante a sua expansão. Por outro lado, conseguem vender os seus produtos a clientes distintos, espacialmente dispersos, sem que haja grandes custos

$\mathrm{e}^{3}$ - Revista de Economia, Empresas e Empreendedores na CPLP | Volume 3 | Número 2 


\section{pontěditora}

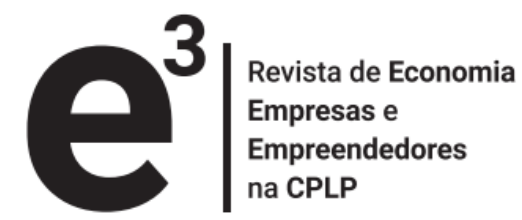

de comunicação, transporte e custos de adaptação. Hennart (2014 p. 117) defende que a principal razão para o sucesso destas empresas é a escolha do modelo de negócio, ou seja: "What they sell, how they sell, and to whom." Outra característica é descrita por Hollensen (2011) que presume que as Born Globals tendem a ser geridas por empresários visionários ou empreendedores, que vêm o mundo como um único mercado, os quais são determinantes na decisão de seguir o caminho da internacionalização. Ao contrário das grandes multinacionais, estas empresas, comummente caracterizadas por serem PME, exibem procedimentos operacionais flexíveis que lhes permitem reagir mais rapidamente a ambientes em mudança e, como refere Laranjeira (2012), conseguem criar e desenvolver um negócio viável, competitivo e sustentável, geralmente com recursos limitados, através da adoção de práticas de negócio flexíveis e inovadoras.

\section{b2) Motivações para a internacionalização}

Num mercado global, as PME precisam reduzir a sua dependência dos mercados domésticos. A AICEP (2013, p. 10) defende que "As atividades internacionais reforçam o crescimento orgânico, aumentam a competitividade e criam condições para a sustentabilidade a longo prazo das empresas". Neste sentido, a diminuição da dependência do mercado interno e a tomada de consciência dos benefícios resultantes de uma estratégia global poderão ser os principais motivos que impulsionam as empresas a seguir o caminho da internacionalização.

A literatura apresenta várias classificações relativamente às motivações para a internacionalização. De facto, a revisão da literatura permite verificar várias propostas relativas às motivações para a internacionalização, as quais estão associadas a factores internos e externos à empresa (Mwiti, Ofafa \& Mkin, 2013; Suaréz-Ortega \& AlamoVera, 2005) e dependem da fase do processo de internacionalização em que a empresa se encontra (Korsakiere \& Baranauskiere, 2011). Outros identificam os motivos como proativos ou reativos (Cavusgill, 1982; Czinkota, Ronkainen \& Moffett, 1999; Hollensen, 2011).

\footnotetext{
2 Dunning $(1998,2001)$ constitui uma das principais referências no âmbito da análise das motivações à internacionalização. Preocupa-se, fundamentalmente, em explicar as razões que determinam a realização de IDE. Uma vez que os casos em análise, neste estudo, constituem PME que não realizam/realizaram IDE, não faremos referência a essa literatura.
} 


\section{pontěditora}

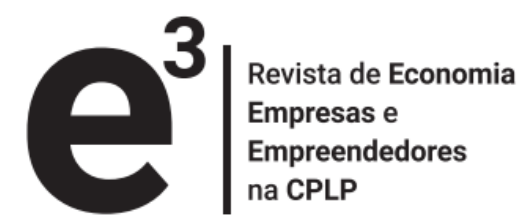

Para Mwiti et al. (2013) os motivos internos são todos os factores que derivam do seio da empresa, enquanto os factores externos são os que decorrem do ambiente externo da empresa. Os autores identificaram como factores relevantes na participação inicial nos mercados de exportação os três seguintes grupos: os factores internos proativos, os factores internos reativos e os factores organizacionais (ver Quadro 1).

\section{Quadro 1 - Tabela Concetual de Factores Motivacionais}

\begin{tabular}{|c|c|c|}
\hline Factores internos proativos & Factores internos reativos & Factores organizacionais \\
\hline Alcançar economias de escala & Gestão de ordens acumuladas & Tamanho da empresa \\
\hline Interesse especial da gestão & $\begin{array}{c}\text { Utilizar capacidade de produção em } \\
\text { excesso }\end{array}$ & Idade da empresa \\
\hline Posse de vantagem competitiva & Manter a venda de produtos sazonais & \\
\hline Potencial para crescimento adicional & $\begin{array}{c}\text { Reduzir a dependência de mercados } \\
\text { domésticos }\end{array}$ & \\
\hline $\begin{array}{c}\text { Produção de bens com características } \\
\text { únicas }\end{array}$ & $\begin{array}{c}\text { Contrabalançar estagnação nas } \\
\text { vendas domésticas }\end{array}$ & \\
\hline
\end{tabular}

Fonte: Adaptado de Mwiti et al. (2013, p. 69)

Czinkota et al. (1999), Hollensen (2011), Masum \& Fernandez (2008) dividem o conjunto de factores que motivam a internacionalização em dois grupos: motivações proativas e motivações reativas. Os motivos proativos indicam que a opção de internacionalização da empresa é influenciada por meios internos e englobam estímulos que se baseiam no interesse da empresa em explorar as suas vantagens competitivas. Com efeito, Czinkota et al. (1999) e Hollensen (2011) agrupam nas motivações proativas as vantagens tecnológicas, os produtos únicos, a informação exclusiva, o compromisso da gestão, os benefícios fiscais e as economias de escala como principais factores motivadores à internacionalização. Os motivos reativos para a internacionalização indicam que a empresa ajusta e altera as suas atividades de forma passiva para dar resposta às pressões ou ameaças do mercado interno ou externo (Hollensen, 2011; Masum \& Fernandez, 2008). Portanto, factores como as pressões da concorrência, o excesso da capacidade produtiva, a saturação do mercado doméstico e a proximidade a clientes e portos de desembarque são apontados como os principais motivos reativos que levam a empresa a internacionalizar as suas atividades.

Com efeito, existem muitas motivações capazes de conduzir as empresas a iniciar o seu processo de internacionalização. Azuay (2016, p.1) refere que "the reason behind going 


\section{pontěditora}

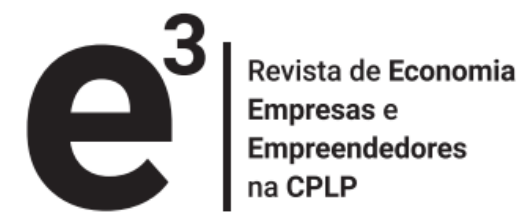

for international market varies from one company to another”. Se algumas motivações são determinadas por uma estratégia definida no seio da empresa, outras motivações derivam de factores externos que levam as empresas a adotarem este comportamento. De um modo geral, percecionamos que as motivações mais referidas pelos vários autores têm sempre, em perspetiva, a possibilidade de crescimento da empresa, maximização do lucro e minimização do custo de aquisição de recursos, e aproveitamento de vantagens competitivas. A influência destes factores, em conjunto com o perfil dos gestores, a dimensão da empresa, bem como as networks que a empresa poderá estar inserida, podem ser os principais impulsionadores da decisão e do reforço do processo de internacionalização.

\section{b3) Modos de entrada em mercados internacionais}

Um modo de entrada no mercado externo pode ser definido como um acordo institucional adotado por uma empresa para facilitar a entrada de bens, tecnologias, recursos humanos, de gestão, entre outros recursos, nesse mesmo mercado (Gao, 2004).

A respeito dos modos de entrada, Hennart et al. (2015, p. 466) referem:

[...] foreign entry into a host market involves the bundling of intangibles contributed by the foreign investor with local complementary inputs contributed by local actors, and that the chosen mode of entry will be the one that maximizes the joint gains of both parties.

A internacionalização não se restringe à transição do produto ou serviço do mercado nacional para o estrangeiro (Fernandes, 2014). As empresas antes de avançarem para os mercados externos, devem ter presente uma estratégia de entrada bem definida e calculada na medida em que, tal como referem Morchett, Schram-Keiln e Swoboda (2010), a definição dos modos de entrada nos mercados externos constitui uma das decisões mais complexas na internacionalização.

Existem diferentes modos de entrada nos mercados externos. A revisão da literatura permite-nos referir que, de um modo geral, são distinguidos os seguintes modos de entrada: 1) a exportação, 2) modo contratual; 3) IDE e 4) a internacionalização através da internet (e-business / e-commerce). De seguida, fazemos uma apresentação, muito resumida, de cada um desses modos. 


\section{pontěditora}

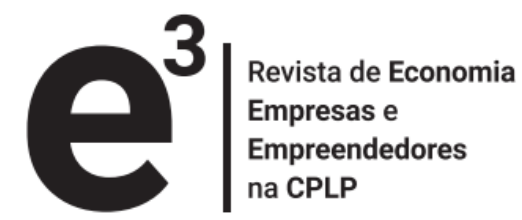

A exportação é a via mais simples de internacionalização e a mais utilizada pelas PME que, devido à falta de recursos, recorrem frequentemente a este tipo de atuação (Hollensen, 2011). Tradicionalmente considerada como o primeiro passo para entrar nos mercados internacionais, a exportação serve frequentemente de plataforma para futuras expansões internacionais (Kiran et al., 2013). Hollensen (2011, p. 337-349) considera três tipos de exportação: a direta, a indireta e o modo de exportação cooperativa. A direta ocorre quando a empresa produtora tem contacto direto com o primeiro intermediário e trata de todos os detalhes da exportação do produto; a indireta, como o próprio nome indica, a empresa produtora não interage diretamente nas atividades exportadoras. Essa interação é feita por outros agentes económicos nacionais, o que faz com que a mesma não tenha qualquer participação nas vendas externas. Para finalizar, o modo de exportação cooperativa, envolve acordos com outras empresas relativamente ao desempenho de funções de exportação

O modo contratual envolve acordos de transferência de bens, conhecimentos, e knowhow entre os mercados de origem e destino. Existem diferentes formas de acordo contratual na internacionalização. Os mais frequentemente utilizados são 0 licenciamento, franchising, alianças estratégicas e Joint Ventures (JV).

O licenciamento é uma forma de negócio que permite que uma empresa conceda a outra, através de um contrato e por um período específico, a exploração de tecnologia, know-how ou de direitos de propriedade (marca, patente, modelos e desenhos), mediante uma remuneração (comummente designada de royalties). É também um dos modos mais utilizados pelas PME porque possibilita à empresa estabelecer, sem grandes custos e riscos, uma base de operações em mercados estrangeiros (Fernandes, 2014). O Franchising é a forma mais alargada do licenciamento, no qual o franchisador, além de transferir o direito de uso do nome da empresa, da marca e da tecnologia, também apoia o franchisado na organização, no marketing e na gestão geral da empresa. Este tipo de contrato tem como objetivo a transmissão de conhecimentos, práticas e uso da marca, em que o dono da marca, o franchisador, recebe uma renda ou franquia (proporcional ao desenvolvimento quantitativo do negócio) do franchisado que, por sua vez, realiza os investimentos necessários à consecução do empreendimento (Cateora et al., 2011). As Alianças Estratégicas constituem acordos de cooperação entre empresas/organizações 


\section{pontěditora}

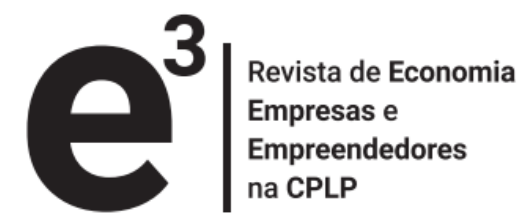

de diferentes países, por meio dos quais decidem partilhar custos, riscos e vantagens de atuar em conjunto nos mercados externos (Hill, 2014). A $J V$ constitui um dos principais exemplos. Este modelo ocorre quando as partes envolvidas concordam em criar uma nova empresa, económica e juridicamente independente, partilhando os lucros, custos, riscos e o controlo sobre o negócio. As $J V$ podem resultar da aquisição parcial de uma sociedade existente no estrangeiro, criação de uma nova empresa em associação com um parceiro local, constituição de uma sociedade conjunta num país terceiro e criação de sociedades mistas com um parceiro local, podendo este ser o Estado ou alguma entidade a ele ligada. Com esta estratégia, a empresa internacional obtém maior controlo sobre as operações, bem como acesso ao conhecimento do mercado local (Azuayi, 2016). O IDE constitui o modo de entrada que envolve maior controlo de mercado mas também o maior risco. De acordo com a OCDE (2008, p. 17) o IDE:

\section{[...] is a category of cross-border investment made by a resident in one economy (the direct investor) with the objective of establishing a lasting interest in an enterprise (the direct investment enterprise) that is resident in an economy other than that of the direct investor. [...] The "lasting interest" is evidenced when the direct investor owns at least 10\% of the voting power of the direct investment enterprise. This entry mode involves greater commitment, costs and risks. Indeed, it involves capital investment (acquisition of assets, establishment of the working team) but also the transfer of knowledge and technology. (Hill, 2014)}

Atualmente, a Internet é considerada uma ferramenta valiosa para as empresas, na medida em que consegue proporcionar-lhes uma presença global mais rápida (isto é, permite a entrada em vários mercados em simultâneo), bem como uma ligação célere com todos os parceiros de negócios. Inclusivamente a internet agilizou o método de distribuição e marketing das empresas o que proporcionou uma fonte diversificada de produtos, tanto para empresas como para os consumidores. Com efeito, a Web permitiu a implementação de novos modelos de negócio, na medida em que permite o acesso à informação e comunicação em qualquer momento e lugar. Sinkovics \& Jean (2013, p.20) afirmam sobre as Born Globals: "seem to be more likely to adopt the Internet for exporting in a more aggressive way and to treat it as an alternative to having a physical presence in foreign markets".

Citando Loane et Bell (2006, p. 264):

$\mathrm{e}^{3}$ - Revista de Economia, Empresas e Empreendedores na CPLP | Volume 3 | Número 2 


\section{pontěditora}

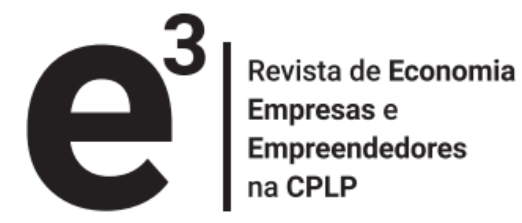

Web access is available to all firms regardless of size, offering benefits which include: reduced importance of economies of scale, lower marketing communication costs, greater price standardization, reduced information float time, temporal asynchronicity, increased contact between buyers and sellers and changes in intermediary relationships.

Apesar das vantagens, existem, no entanto, alguns factores que dificultam a tomada de decisão estratégica sobre o posicionamento das empresas na internet. Se as empresas não venderem os seus produtos diretamente pela internet, essa decisão pode levar alguns clientes a procurarem a concorrência. Por outro lado, se o fizerem, pode provocar problemas com distribuidores e agentes, que podem passar a vender apenas produtos e serviços de fabricantes que não concorram diretamente neste canal. Adicionalmente, a evolução do e-commerce fez também aumentar os níveis de concorrência entre atores, pois a quantidade de empresas a competir no mercado global tornou-se maior.

A revisão da literatura apresentada e relativa à temática da internacionalização, principais teorias e modelos de internacionalização, as motivações e os modos de entrada nos mercados internacionais, indica que a abordagem que as empresas fazem aos mercados internacionais depende do modelo de negócio, do produto e da forma como operam. Uma empresa, quando decide atuar em mercados externos, deve conhecer claramente os seus objetivos e motivações, assim como deve estar consciente das implicações que um processo de internacionalização pode proporcionar (Ivarsson \& Johan, 1998). Por exemplo, Fernandes (2014) refere que é a produtividade que conduz à competitividade e indica quatro variáveis que todas as empresas devem ter em conta: a qualidade, o preço, o prazo de resposta e a criação de valor para o cliente. Na nossa perspetiva, o processo de internacionalização pode constituir uma estratégia complexa, que envolve risco, incerteza, introdução de novos comportamentos e mudanças estruturais. Num quadro de globalização, a empresa terá que possuir e/ou criar factores de diferenciação que lhe permitam manter uma vantagem competitiva sustentável porque isso irá determinar o seu sucesso/insucesso em qualquer mercado.

\section{c) Metodologia}

O objetivo fundamental do estudo é analisar e explicar o processo de internacionalização adotado por três PME portuguesas (descritas no quadro 2) e procurar perceber de que forma abordam os mercados internacionais. Em específico, 


\section{pontěditora}

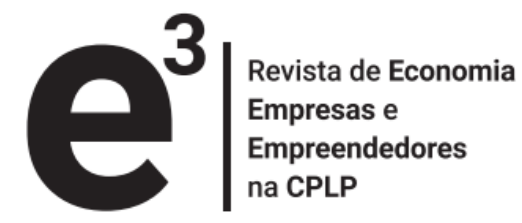

pretende-se obter resposta às seguintes questões: Que factores motivam e influenciam o PI? Que estratégias e modalidades escolhem? Que factores de diferenciação possuem que lhes permitem competir nos mercados internacionais?

As razões que justificam a opção de análise destas empresas foram já anteriormente explanadas. Atendendo aos objetivos para a elaboração do trabalho, ao analisar o PI das empresas é importante confrontar os modelos teóricos com a prática empresarial. Dado que se pretende uma descrição completa e pormenorizada do objeto de estudo, seguimos a metodologia qualitativa, utilizando como método o estudo de caso. Segundo Bluhm, Harman, Lee e Mitchell (2011), a investigação qualitativa torna-se fundamental para descobrir processos mais específicos em indivíduos, grupos, organizações e entender como esses processos se desenrolam ao longo do tempo. De entre os diferentes métodos de investigação qualitativa, o estudo de caso é o mais utilizado na área dos negócios internacionais (Piekkari, Welch \& Paavilainen 2009).

Para Yin (2009), o estudo de caso é o recurso metodológico mais indicado quando o investigador procura dar resposta a questões do tipo "como?" e "porquê?", e pode ser definido como uma pesquisa empírica que tem como objetivo, explorar, explicar ou descrever um tema atual dentro do seu contexto real, principalmente quando o investigador tem pouco controlo sobre os eventos em causa e quando o enfoque está sobre um fenómeno contemporâneo. Yin (2009) alerta, no entanto, para o facto de este método de investigação poder apresentar falta de rigor na investigação, poder fornecer pouca base para uma generalização científica, bem como para o facto do investigador poder, de alguma forma, "corromper" o estudo, através de visões tendenciosas que podem influenciar o resultado das conclusões. Adicionalmente, Yin (2009) considera que o mesmo estudo pode analisar vários casos, sendo preferível esta abordagem àquela que utiliza apenas um caso, pois permite verificar a convergência dos mesmos ou distinguir situações contrastantes.

Neste estudo, a recolha de dados foi efetuada essencialmente através de três entrevistas semi-estruturadas, aos responsáveis pela internacionalização da empresa, com perguntas abertas (obedecendo a um guião pré-elaborado). Além das entrevistas e respetiva recolha de dados primários, neste trabalho, efetuou-se também a análise documental e 


\section{pontěditora}

recolha de dados secundários, recolhidos nos sites das empresas, notícias em sites, revistas e jornais) ao que vários autores chamam de "triangulação de dados".

\section{d) Estudo de caso - análise e discussão}

Considerando os dados recolhidos, apresentamos, no Quadro 2, de forma resumida, a caracterização das três empresas.

Quadro 2 - Caracterização das empresas em estudo

\begin{tabular}{|c|c|c|c|}
\hline \multirow[t]{2}{*}{ CARACTERIZAÇÃO } & \multicolumn{3}{|c|}{ EMPRESAS } \\
\hline & $\begin{array}{c}\text { Arcaboa - Indústria de Frio, } \\
\text { S.a. }\end{array}$ & $\begin{array}{l}\text { Paulo Antunes - } \\
\text { Unipessoal, Lda. }\end{array}$ & VentureOak \\
\hline $\begin{array}{l}\text { CAE e ramo de } \\
\text { atividade }\end{array}$ & $\begin{array}{c}28250 \text { - Fabricação de } \\
\text { equipamento não doméstico } \\
\text { para refrigeração e ventilação }\end{array}$ & $\begin{array}{c}31091 \text { - Fabricação de } \\
\text { mobiliário de madeira } \\
\text { para outros fins }\end{array}$ & $\begin{array}{c}\text { 62010-R3 - Atividades } \\
\text { de programação } \\
\text { informática }\end{array}$ \\
\hline $\begin{array}{l}\text { Tipo de produtos/ } \\
\text { serviços que vende }\end{array}$ & $\begin{array}{l}\text { Arcas congeladoras, expositores } \\
\text { profissionais para } \\
\text { supermercados, congeladores } \\
\text { profissionais; }\end{array}$ & Estofo e mobiliário & $\begin{array}{c}\text { O desenho e } \\
\text { desenvolvimento de } \\
\text { soluções } e \text {-commerce } \\
\text { de raiz; } \\
\text { análise, consultoria e } \\
\text { implementação de } \\
\text { soluções de tecnologia } \\
\text { e de negócio }\end{array}$ \\
\hline Génese da empresa & 1981 & 2000 & 2013 \\
\hline $\begin{array}{l}\text { No colaboradores: } \\
\text { antes } \\
\text { pós- } \\
\text { internacionalização }\end{array}$ & $\begin{array}{l}10 \\
42\end{array}$ & $\begin{array}{c}6 \\
25\end{array}$ & $\begin{array}{c}2 \\
21\end{array}$ \\
\hline $\begin{array}{c}\text { Ano de } \\
\text { internacionalização }\end{array}$ & $1988 / 1989$ & 2000 & 2013 \\
\hline Responsável pelo PI & Rogério Sousa & Paulo Antunes & Miguel Garcia \\
\hline $\begin{array}{c}\text { Volume das } \\
\text { exportações } \\
\text { sobre as vendas }\end{array}$ & $\begin{array}{l}82 \text { a } 83 \% \text { (percentagem } \\
\text { referente ao ano 2014) }\end{array}$ & $\begin{array}{c}85,25 \% \text { (referente ao } \\
\text { ano 2014) }\end{array}$ & $\begin{array}{c}36 \% \text { (percentagem } \\
\text { referente ao ano 2015). } \\
\text { Em } 2014 \text { a empresa } \\
\text { não teve projetos para } \\
\text { o estrangeiro) }\end{array}$ \\
\hline Mercados externos & $\begin{array}{l}\text { Coreia do Sul, Taiwan, Rússia, } \\
\text { Indonésia,Turquia, } \\
\text { Moçambique, Angola, África do } \\
\text { Sul, Espanha, França, Itália, } \\
\text { Dinamarca, Suíça, Alemanha, } \\
\text { Suécia, Grécia, Chipre, Malta, } \\
\text { Hungria, Inglaterra, Holanda, } \\
\text { Bélgica, Polónia, Cuba, Santo } \\
\text { Domingo, San Martín, Chile, } \\
\text { Perú, Israel, Libano, Dubai }\end{array}$ & $\begin{array}{l}\text { Alemanha, Espanha, } \\
\text { América, França, } \\
\text { Dinamarca, Itália, } \\
\text { Inglaterra, Bélgica, } \\
\text { Finlândia, Egipto, } \\
\text { Mongólia, Rússia, } \\
\text { Arábia Saudita, Nova } \\
\text { Zelândia, Singapura, } \\
\text { Holanda, Noruega, } \\
\text { Suécia }\end{array}$ & $\begin{array}{l}\text { Índia, Nigéria, Egito, } \\
\text { Quénia, Marrocos, } \\
\text { Moçambique, África } \\
\text { do Sul, Alemanha, } \\
\text { Suíça, Áustria, } \\
\text { Filipinas, Indonésia }\end{array}$ \\
\hline
\end{tabular}

Fonte: Elaboração própria

\section{d1) Análise e discussão dos casos}




\section{pontěditora}

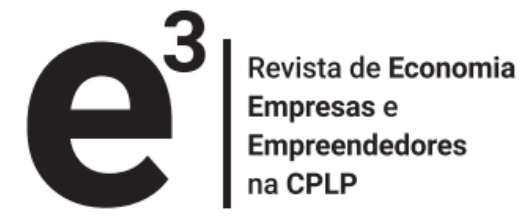

A análise privilegiou o cruzamento das respostas obtidas nas entrevistas, e nas outras fontes de informação, com o enquadramento teórico da temática no sentido de responder, de forma sucinta e objetiva, às questões de investigação propostas. Dado o método seguido, temos que ressalvar que as conclusões a que chegamos estão limitadas aos casos em estudo, não podendo ser generalizadas ao universo de empresas que se internacionalizam. Não obstante, podemos apresentar algumas conclusões relativas ao enquadramento dos casos em estudo com a literatura e a teoria revista.

\section{Resposta às questões de investigação}

1.1 Que factores motivam e influenciam o PI?

No que concerne às razões que motivam e influenciam o PI das empresas, o estudo destas três PME portuguesas indica que existem várias razões que motivam e influenciam a sua internacionalização. Em modo de síntese, o crescimento da empresa (uma das motivações proativas referidas por Mwiti et al., 2013; Czinkota et al.,1999; Hollensen, 2011) e o interesse especial da gestão (Mwiti et al., 2013) são dois dos factores que se mostraram relevantes para a fase inicial da internacionalização das 3 empresas. Verificamos ainda que, devido ao modelo de negócio da VentureOak, a empresa apresentou motivações reativas (abordadas por Hollensen, 2011; Masum \& Fernandez, 2008). A empresa, para além de sentir necessidade de atuar desde o início num mercado de maior dimensão e o facto de não ter acesso a projetos nacionais, potenciou a vontade de internacionalizar-se. 


\section{pontěditora}

\subsection{Que estratégias e modalidades escolhem?}

A definição dos modos de entrada nos mercados externos constitui uma das decisões mais complexas na internacionalização (Morschett, et. al, 2010). Particularmente nestes casos, apesar das empresas conhecerem a heterogeneidade dos mercados que abordam, o único modo de entrada utilizado é o da exportação direta (através de agentes, distribuidores ou contractors). Adicionalmente, podemos referir que a escolha de três PME de ramos de negócio muito distintos foi propositada na medida em que poderia, à partida, evidenciar diferenças na forma como abordam os mercados internacionais. Contudo, para os casos em estudo, verificou-se que todas usaram o mesmo modo de entrada. As razões que justificam a escolha deste modo de entrada não foram explicitamente obtidas durante a recolha de dados mas, segundo autores como Hollensen (2011), a exportação é a via mais simples de internacionalização e a mais utilizada pelas PME que, devido à falta de recursos, recorrem frequentemente a este tipo de atuação. Porém, apesar da exportação ser considerada a base primária da internacionalização, o facto das PME usarem a exportação direta permite que as mesmas tenham acesso à experiência no mercado local, permitindo mais conhecimento sobre o país de destino, bem como maior controlo das atividades.

\subsection{Que factores de diferenciação possuem que lhes permitem competir nos mercados internacionais?}

Relativamente aos fatores de competitividade, todas as empresas identificaram três das variáveis propostas por Fernandes (2014): a qualidade, preço e prazo de entrega. Particularmente, a VentureOak referiu que a importância destas variáveis varia conforme o mercado. Se nos mercados desenvolvidos dão mais valor à qualidade, os mercados em desenvolvimento vão muito pelo preço. A variável "tempo" é muito importante para este ramo de atividade. A empresa refere que todos os mercados esperam que o prazo de desenvolvimento do produto seja curto. 


\section{pontěditora}

\section{Discussão}

A análise das respostas e dos PI das três empresas permitiu-nos, analisar a aplicabilidade dos modelos teóricos, bem como verificar algumas similaridades, mas também algumas divergências relativamente ao modo como abordam os mercados internacionais. Esta constitui, segundo Yin (2009) uma vantagem da análise multi-caso comparativamente à abordagem que utiliza apenas um caso, porque permite verificar a convergência dos mesmos ou distinguir situações contrastantes.

Com efeito, as respostas e a análise do PI de cada empresa indica-nos que, na nossa perspetiva, as teorias que melhor os explicam são: o Modelo de Uppsala - teoria que explica como as empresas intensificam gradualmente as suas atividades nos mercados internacionais (Johanson \& Vahlne, 1977) e a Teoria das Born Globals ou INV, que procura justificar o PI de empresas mais dinâmicas que iniciam a sua internacionalização aquando da sua origem ou pouco tempo depois (Rennie, 1993; McDougall \& Oviatt, 1994).

Portanto, o caso Arcaboa enquadra-se, em vários aspetos, na teoria Uppsala, como por exemplo: o primeiro mercado a ser abordado foi o espanhol, e isto deveu-se a factores como a linguagem, cultura e por ser geograficamente mais próximo. Conforme vimos no enquadramento teórico, segundo Benito e Grisrud, (1992) estes factores encaixam no conceito de "distância psicológica" proposto no modelo. Além disso, a abordagem aos restantes mercados foi feita "passo a passo" de forma gradual, de acordo com uma cadeia sequencial de comprometimento crescente (Johanson \& Vahlne, 1977, p. 26). Só mais tarde, quando a empresa já detinha alguma experiência internacional, e possuía mais recursos, fez um comprometimento de mercado mais profundo: investiu na penetração de mercados fora da Europa e solidificou as suas atividades comerciais nos mercados em que já operava. Porém, esta empresa não segue todas as fases sequenciais propostas pela teoria. Apesar do seu comprometimento de mercado ser cada vez maior, a exportação sempre foi o seu modo de entrada, não evoluindo para as fases seguintes.

A Paulo Antunes é um exemplo de que o PI das empresas pode não obedecer a um modelo pré-definido. Se por um lado possui as características de uma Born Global: começou a sua internacionalização aquando da sua origem (Rennie, 1993), fruto da 


\section{pontěditora}

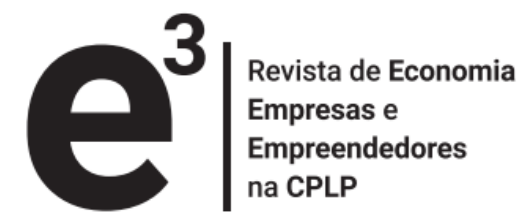

vontade do gerente, um empreendedor que sempre considerou o mercado europeu como um mercado interno (Hollensen, 2011), e assumiu elevados riscos na fase inicial da sua expansão. Por outro lado, a empresa passou pelas fases sequenciais de exportação (exportava esporadicamente e só mais tarde é que passou para a exportação através de agentes e contractors) um dos aspetos defendidos pelo modelo Uppsala e que indica que o PI é feito de forma evolutiva e gradual.

O PI da VentureOak indica que a empresa é uma Born Global por vários motivos: a empresa iniciou o seu processo no mesmo ano da sua origem; pelo carácter empreendedor fundador da empresa, que vê o mundo como um único mercado; pelo facto de possuir recursos tecnológicos e humanos notáveis; bem como pelo seu modelo de negócio e a forma como operam possibilitando à empresa vender os seus produtos a clientes distintos e geograficamente dispersos.

As respostas obtidas nesta pesquisa também permitem perceber a importância que as redes de relacionamento, ainda que não sejam formais, têm para a forma como as mesmas abordam os mercados (Modelo Uppsala e a perspetiva das Networks). As relações com outros players do ramo ou de setores que se complementam (agentes, distribuidores, contractors) é demonstrada, ainda que informalmente. As empresas referiram que estas relações as ajudaram a abordar e entrar em novos mercados internacionais.

\section{e) Conclusões e limitações}

A rápida e constante evolução do cenário mundial, em que as empresas competem, justifica a relevância que o tema da internacionalização tem assumido. No contexto nacional, a internacionalização das empresas é um facto que está na ordem do dia e a conjuntura económica incentiva cada vez mais as empresas à internacionalização.

Esta pesquisa procurou, fundamentalmente, obter resposta a três questões: Que factores motivam e influenciam o PI das PME? Que estratégias e modalidades escolhem? Que factores de diferenciação possuem que lhes permitem competir nos mercados internacionais? Ressalvando que, por razões metodológicas, as conclusões estão limitadas aos casos em estudo, não podendo ser generalizadas ao universo de empresas que se internacionalizam, esta pesquisa permite, contudo, apresentar algumas 


\section{pontěditora}

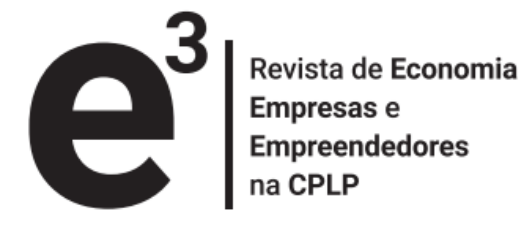

conclusões relativas ao enquadramento dos casos em estudo com a literatura e a teoria revista.

Contrapondo os casos, concluímos que não existe apenas um modelo teórico que explique o PI de todas as empresas. Os resultados indicam que alguns aspetos defendidos pelo modelo Uppsala são muito úteis para compreender o PI das PME, apesar de nenhuma das empresas em estudo seguir todos os passos descritos neste modelo. No entanto, também indicam que existem empresas que, devido ao seu modelo de negócio, à forma como operam e ao carácter empreendedor do fundador da empresa, iniciam a sua expansão internacional no mesmo ano da sua origem. As Born Globals conseguem vender os seus produtos a clientes distintos e geograficamente dispersos, devido ao seu modelo de negócio, do produto e da forma como operam, divergindo de algumas ideias do modelo Uppsala, pois o processo de internacionalização, nestes casos, não se trata de um processo nem lento nem moroso.

A análise dos casos, em estudo, permite concluir que a exportação é a estratégia e o modo de entrada mais viável para estas PME. Em comum, as empresas apresentam a propensão para a exportação através da abordagem direta ao cliente, o que possibilita um risco menor e permite ainda uma maior experiência internacional, pois facilita o contacto direto com os mercados.

As empresas procuram os mercados internacionais sobretudo por motivos de crescimento e de sobrevivência, tendo como principal justificação a exiguidade do mercado interno. A abordagem que as empresas fazem aos mercados internacionais, depende do modelo de negócio, do produto e da forma como operam. Além destas razões, o perfil dos gestores, o modelo de negócio, bem como as networks que a empresa poderá estar inserida, parecem ser os principais impulsionadores da decisão e do reforço do PI. Para finalizar, percebe-se que existe uma crescente consciencialização das empresas para a importância de garantir uma vantagem competitiva. Nesse sentido, todas as PME em estudo têm em consideração que os factores de qualidade, o preço e o prazo de entrega são determinantes para o sucesso.

As principais limitações desta pesquisa estão associadas à abordagem qualitativa e ao método utilizado, bem como à limitação da amostra, por dificuldades sentidas em obter respostas e disponibilidade das empresas. Nesse sentido, em trabalhos futuros seria 


\section{pontěditora}

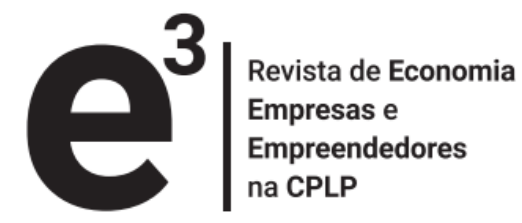

importante realizar um estudo quantitativo, utilizando, por exemplo, os inquéritos, de forma a alargar a amostra de empresas em estudo. Consideramos ainda que poderia ter interesse fazer uma análise intra-setor ou ramo de atividade, bem como uma análise comparativa para diferentes setores, no sentido de perceber se há ou não diferenças nos motivos, modos e estratégias de internacionalização e quais as razões que justificam essas potenciais diferenças/semelhanças.

\section{f) Referências}

Amal, M., Filho, A. \& Miranda, C., (2008). Algumas evidências sobre o papel das redes de relacionamento e empreendedorismo na internacionalização das pequenas $e$ médias empresas. FACES R. Adm. Belo Horizonte · v. 7 n. 1, 63-80.

AICEP Portugal Global. (03 de 07 de 2013). Horizonte Internacionalizar: Guia para $P M E$. Obtido a 27 de novembro de 2014.

Andersen, O. \& Buvik, A. (2002). "Firms Internationalization and ALternative Approaches to the International Customer/ Market Selection". International Business Review, 11, 347-363.

Anderson, O. (1997). "Internationalization and Market Entry Mode: A Review of Theories and Conceptual Framework". Management International Review, $27 n^{o}$ 2, 27-42.

Azuayi R (2016). "Internationalization Strategies for Global Companies: A Case Study of Arla Foods, Denmark". J Account Mark 5: 191. doi:10.4172/21689601.1000191. Obtido a 31 de março de 2017.

Benito, G. \& Gripsrud, G. (1992). "The Expansion of Foreign Direct Investments: discrete racional location choices or a cultural learning process?". Journal of International business Studies, $23 n^{\circ}$ 3, 461-476.

Bluhm, D., Harman, W., Lee, T. W. \& Mitchell, T. R. (2011). Qualitative Research in Management: A Decade of Progress, Journal of Management Studies 48:8 December.

Buckley, P. \& Casson, M. (1976). The Future of the Multinational Enterprise. New York: Homes and Meier.

Buckley, P. \& Casson, M. (1998). “Analyzing Foreign Market Entry Strategies: Extending the Internalization Approach". Journal of International Business Studies, 29, $n^{\circ} 3,539-562$. 


\section{pontěditora}

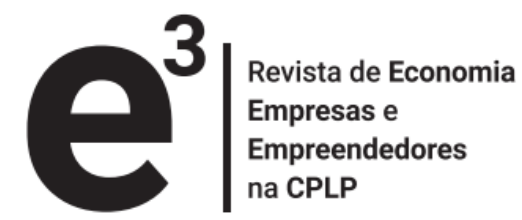

Cannone, G. \& Ughetto, E. (2014). "Born Globals: Across-Country survey on high-tech strat-ups". International Business Review, $23 n^{\circ}$ 1, 272-283.

Cateora, P. Gilly, M. \& Graham, J. (2011). International Marketing (15 ${ }^{\text {a }}$ ed.). New York: McGraw-Hill Companies, Inc.

Cavusgil, S. T. (1982). "Decision-making for International Marketing: A comparative Review". Management Decision, $20 n^{\circ}$ 4, 47-54.

Comissão Europeia. (2010). Internationalisation of European SMEs Final Report. Entrepreneurship Unit Directorate-General for Enterprise and Industry. Obtido a 14 de janeiro de 2015, de http://ec.europa.eu/enterprise/policies/sme/marketaccess/files/internationalisatio n_of_european_smes_final_en.pdf.

Conconi, P; Sapir, A.; Zanardi M. (2015). "The internationalization process of firms: From exports to FDI". Journal of International Economics 99, p. 16-30. http://dx.doi.org/10.1016/j.jinteco.2015.12.004.

Czinkota, M., Ronkainen, I. \& Moffett, M. (1999). International Business (5 ${ }^{\mathrm{a}}$ ed.). Orlando: Dryden Press, Fort Worth.

Ducuing, P-B. \& Gallo, A. (2010). Internet and the Internationalization Process of SMEs. Two Northern Swedish cases. Master in Business Development and Internationalization. UMEA School of Business, Sweden. Obtido de Disponível em: http://www.diva-portal.se/smash/get/diva2:326982/FULLTEXT01.pdf.

Dunning, J. H. (1973). "Explaining Changing of International Production: in defense of the ecletic theory". Oxford Economic Papers, 11, $n^{\circ} 3,289-336$.

Dunning, J. H. (1988). “The Ecletic Paradigm Of International Production. A Restament and Some Possible Extensions". Journal Of International Business Studies, 9, $n^{o}$ $1,1-31$.

Dunning, J. H. (2000). "The Ecletic Paradigm as an Envelope for Economic and Business Theories of MNE Activity". International Business Review, 9, $n^{o}$ 2, 163-190.

Dunning, J. H. (2001). The Ecletic (OLI) "Paradigm of International Production: Past, Present and Future". Journal of the Economics of Business, 8, $n^{\circ} 2,173-190$.

Fernandes, J. M. (2014). Caminhos do Exportador. Estratégias de internacionalização. Coimbra: Conjuntura Actual Editora. 


\section{pontěditora}

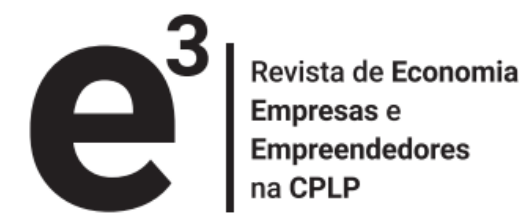

Gao, T. (2004). “The Contingency Framework Of Foreign Entry Mode Decisions: Locating and Reinforcing the Weaskest Link". The Multinational Business Review, 12, $n^{o} 1,37-68$.

Hagiu, A. \& Clipici, E. (2009). The Internationalization Strategy in a Global Age. The International Conference on Economics and Administration, Faculty of Administration and Business, University of Bucharest, Romania ICEA - FAA Brucharest, 14-15th.

Hennart, J. (2014). "The Accidental Internationalists; a Theory of Born Globals". Entrepreneurship Theory and Practice, $38 n^{\circ} 1,117-135$.

Hennart, J., Sheng, H. \& Pimenta, G. (2015). "Local complementary inputs as drivers of entry mode choices. The case of US investments in Brazil". International Business Review, 466-475.

Hill, C. W. (2014). International Business: competing in the global marketplace. 10th Global Edition. . McGrawHill Education.

Hollensen, S. (2011). Global Marketing: A Decision-oriented Approach (5 ${ }^{\mathrm{a}}$ ed.). Prentice Hall Financial Times.

Ivarsson, A. \& Johan, O. (1998). The Internationalisation Possibilities For a Small, Fast, Growing and Knowledge Intensive Company. Sweden: Linköping University.

Jarillo, J. C. (1989). "Entrepreneurship and Growth: the strategic use of external resources". Journal of Business Vanturing, $4 N^{o} 2$, 133-147.

Johanson, J. \& Vahlne, J. (1977). "The Internationalization Process of the Firm - A model of knowledge development and increasing foreign market commitment". Journal of International Business Studies, 8 (1), 23-32.

Johanson, J. \& Vahlne, J. (2006). “Commitment and Opportunity Development in the Internationalization Process. A Note in the Uppsala Internationalization Process Model'. Management International Review, 46, $n^{\circ}$ 2, 165-178.

Johanson, J. \& Vahlne, J. (2009). “The Uppsala Internationalization Process Model Revisited: From liability of foreignness to liability of outsidership". Journal of International Business Studies, 40, nº 9, 1411-1431.

Johanson, J. \& Wiedersheim-Paul, F. (1975). "The Internationalization of the Firm: four Swedish cases". Journal of Management Studies, 12, 305-322. 


\section{pontěditora}

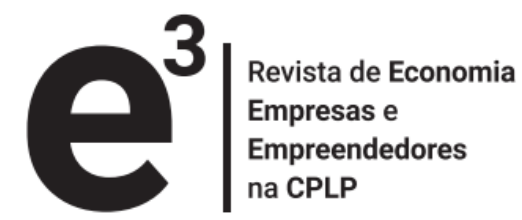

Kiran, V., Majumdar, M. \& Kishore, K. (2013). "Internationalization of SMEs: Finding a Way Ahead". American International Journal of Research in Humanities, Arts and Social Sciences, 18-23.

Knight, G. (2000). "Entrepremeurship and Marketing Strategy: the SME under globalization". Journal of International Marketing, $8 N^{o}$ 2, 12-32.

Korsakiere, R. \& Baranauskiere, A. (2011). "Factors Impacting Sustainable Internationalization: a case of multinational company". Journal of Security and Sustainability Issues, 1, 53-62.

Laranjeira, A. S. (2012). O Impacto do Empreendedor Internacional nas Born Globals. Dissertação de mestrado. Universidade Católica, Faculdade de Economia e Gestão.

Loane, S. e Bell, J. (2006). "Rapid internationalization among entrepreneurial firms in Australia, Canada, Ireland and New Zealand: An extension to the network approach". International Marketing Review, Vol. 23, No. 5, pp. 467-485.

Masum, M. \& Fernandez, A. (2008). Internationalization Process of SMES: Strategies and Methods. Master Thesis Mälardalen University School of Sustainable Development of Society and Technology - Västeras Sweden. Obtido a 30 de dezembro de 2014.

McDougall, P., Shane, S. \& Oviatt, B. (1994). "Explaining the Formation of International Nex Ventures: The Limits of Theories from International Business Research". Journal of Business Venturing, $9 n^{\circ}$ 6, 469-487.

Morschett, D., Schram-Keiln, H. \& Swoboda, B. (2010). "Decades of Research on Market Entry Modes: What do we really know about external antecedents of entry mode choice?". Journal of International Management, $16 n^{\circ}$ 1, 60-77.

Mwiti, E., Ofafa, G. \& Mkim, A. (2013). "Determinants of Initial Export Market Participation (an empirical study on the internal-proative and internal reative factors among small enterprises in the comercial craft sector in Kenya)". International Journal of Business and Social Science, $4 n^{\circ} 7,64-88$.

OECD (2008). Benchmark Definition of Foreign Direct Investment. Four edition 2008. Obtido: https://www.oecd.org/daf/inv/investmentstatisticsandanalysis/40193734.pdf a 28 de junho de 2016

Oviatt, B. \& McDougall, P. (1994). "Towards a Theory of New Ventures". Journal of International Business Studies, $25 n^{\circ}$ 1, 45-64. 


\section{pontěditora}

Piekkari, R. \& Welch, C. (2011). Rethinking the Case Study in International Business and Management Research, Cheltenham, Edward Elgar Publishing

Rennie, M. (1993). “Global Competitiveness: Born Global”. Mckinsey Quarterly, 4552.

Sinkovics, N., Sinkovics, R. \& Jean, R. (2013). "The Internet as an Alternative Path to Internationalization". International Marketing Reviwe, $30 n^{\circ}$ 2, 130-155. Obtido de https://www.escholar.manchester.ac.uk/api/datastream?publicationPid=uk-acman-scw: $167062 \&$ datastreamId=POST-PEER-REVIEW-NON-

PUBLISHERS.PDF Pre print (non-publishers document)

Stoian, C. \& Filippaios, F. (2008). "Dunning's Ecletic Paradigm: A holistic, yet context specific framework for analysing the determinants of outward FDI: Evidence from Greek insvestiments”. International Business Review, $17 n^{\circ}$ 3, 349-367.

Suárez-Ortega, M. \& Alamo-Vera, F. (2005). "SMEs Internationalization: Firms and Managerial Factors". International Journal of Entrepreneurial Behaviour \& Research, 11 n $^{\circ}$ 4, 258-279.

Welch, L. S. \& Luostarinen, R. (1988). "Internationalization: Evolution of a Concept". Journal Of General Management, 2, 34-55.

Yin, R. K. (2009). Case Study Research. Design and Methods (4 th ed.). London:

Thousand Oaks: Sage Publication.

\section{(cc) $\mathrm{BY}-\mathrm{NC}-\mathrm{SA}$}

O trabalho $\mathrm{e}^{3}$ - Revista de Economia, Empresas e Empreendedores na CPLP está licenciado com uma Licença Creative Commons - Atribuição-NãoComercial-Compartilhalgual 4.0 Internacional. 